\title{
Induction of apoptosis by isothiocyanate sulforaphane in human cervical carcinoma HeLa and hepatocarcinoma HepG2 cells through activation of caspase-3
}

\author{
SOUNG YOUNG PARK ${ }^{1-3}$, GI YOUNG KIM ${ }^{4}$, SONG-JA BAE ${ }^{3}$, YOUNG HYUN YOO ${ }^{5}$ and YUNG HYUN CHOI ${ }^{1}$ \\ ${ }^{1}$ Department of Biochemistry, Dongeui University College of Oriental Medicine and ${ }^{2}$ Department of Biomaterial Control \\ (BK21 program), Dongeui University Graduate School, Busan 614-052; ${ }^{3}$ Department of Food and Nutrition, Silla University \\ and Marine Biotechnology Center for Bio-Functional Material Industries, Busan 617-736; ${ }^{4}$ Faculty of Applied Marine \\ Science, Cheju National University, Jeju 690-756; ${ }^{5}$ Department of Anatomy and Cell Biology, Dong-A University \\ College of Medicine and Medical Science Research Center, Busan 602-714, South Korea
}

Received March 10, 2007; Accepted April 24, 2007

\begin{abstract}
Sulforaphane (SFN) is an isothiocyanate that is found in abundant quantities in many cruciferous vegetables including broccoli and cauliflower. Its inhibitory effects on tumor cell growth in vitro and in vivo, which is dependent on the direct effect on cancer cells, has attracted considerable attention. This study examined the effects of SFN on the growth of human cervical carcinoma HeLa and hepatocarcinoma HepG2 cells. The results showed that SFN inhibits the viability of both HeLa and HepG2 cells by inducing apoptosis, as evidenced by the formation of apoptotic bodies and the accumulation of the sub-G1 phase. RT-PCR and immunoblotting showed that treating the cells with SFN caused the down-regulation of anti-apoptotic Bcl-2 and Bcl$\mathrm{X}_{\mathrm{L}}$, and the up-regulation of pro-apoptotic Bax expression. $\mathrm{SFN}$-induced apoptosis was associated with the proteolytic activation of caspase-3, and the degradation/cleavage of poly (ADP-ribose) polymerase and the $\beta$-catenin protein. z-DEVDfmk, a caspase-3 specific inhibitor, blocked the activation of caspase- 3 and increased the survival of the SFN-treated HeLa and HepG3 cells, suggesting that caspase- 3 activation is essential for SFN-induced apoptosis.
\end{abstract}

\section{Introduction}

Apoptosis is a highly regulated process of programmed cell death that involves the activation of a series of molecular events, which is characterized by cell shrinkage, blebbing of

Correspondence to: Dr Yung Hyun Choi, Department of Biochemistry, Dongeui University College of Oriental Medicine, Busan 614-052, South Korea

E-mail: choiyh@deu.ac.kr

Dr Young Hyun Yoo, Department of Anatomy and Cell Biology, Dong-A University College of Medicine and Medical Science Research Center, Busan 602-714, South Korea

E-mail: yhyoo@dau.ac.kr

Key words: sulforaphane, apoptosis, Bcl-2 family, caspase-3 the plasma membrane, and chromatin condensation that is consistent with DNA cleavage in the ladder $(1,2)$. Apoptosis is a fundamental cellular activity that is essential for maintaining the physiological balance of an organism. It is involved in the immune defense machinery and plays an important role as a protective mechanism against carcinogenesis by eliminating damaged cells or the abnormal proliferation of cells (3). Several genes have been identified to either induce or repress apoptosis. Caspases play a key role in the execution phase of cell death through various apoptotic stimuli (4). These cysteine-related proteases are present in cells as inactive proenzymes, with the active tetramer being formed by the removal of the prodomain and cleavage between the large and small subunits. The caspase activity is responsible, either directly or indirectly, for the cleavage of several intracellular proteins, which are characteristically proteolysed during apoptosis (4). The processing and activation of caspases can be regulated by molecules such as Bcl-2 as well as by members of the inhibitor of the apoptosis protein (IAP) family (5). In most cases, apoptosis involves the release of cytochrome $c$ from the mitochondria. In the cytosol, cytochrome $c$ activates caspase-9, which in turn activates the effector caspases such as caspase-3. Bcl-2 and its related proteins control the release of cytochrome $c$ from the mitochondria, whereas IAP molecules modulate the activity of caspases through a direct interaction with the active caspases $(4,5)$. Accumulated data indicate that many chemotherapeutic agents can cause the death of tumor cells through the induction of apoptosis, which is the preferred way of managing cancer.

Many epidemiological studies have shown that the regular consumption of fruits and vegetables has an inhibitory effect on the development of cancer (6). Therefore, it is important to identify the natural products of fruits and vegetables as well as to identify the molecular pathway(s) responsible for their effects on cancer cells. Isothiocyanates (ITCs) are widely distributed in cruciferous vegetables such as broccoli, cabbage, gardencress, cauliflower and Brussels sprouts (7). Naturally occurring ITCs have significant chemopreventive activity against chemically induced cancer in animal models $(8,9)$. 
Sulforaphane [1-isothiocyanato-4-(methyl-sulfinyl)butane; $\mathrm{CH}_{3}-\mathrm{SO}-\left(\mathrm{CH}_{2}\right)_{4}-\mathrm{N}=\mathrm{C}=\mathrm{S}$ ] $(\mathrm{SFN})$ is one of the ITCs most commonly studied. SFN was first isolated from broccoli as a potent inducer of the phase II detoxification enzymes, and was found to inhibit the phase I enzymes that activate chemical carcinogenesis $(10,11)$. More recent studies have suggested that SFN inhibits the proliferation of cancer cells in culture by causing cell cycle arrest and apoptosis (12-24), however, the molecular mechanisms of curcumin in malignant cells are not yet clearly understood.

This study examined the antiproliferative activity of SFN along with its effect on the apoptosis of human cervical carcinoma HeLa and hepatocarcinoma HepG2 cells. Furthermore, the levels of several important genes that are strongly associated with the signal transduction pathway of apoptosis were assayed to establish the anticancer mechanism of SFN as a potential chemopreventive agent.

\section{Materials and methods}

Cell culture and cell viability assay. Human cervical carcinoma HeLa and hepatocarcinoma HepG2 cells were purchased from the American Type Culture Collection (Rockville, MD). Both cell lines were cultured in Dulbecco's modified Eagle's medium (DMEM) containing 100 units/ml penicillin/streptomycin and supplemented with $10 \%$ heat-inactivated fetal bovine serum (FBS, Gibco BRL, Gaithersburg, MD) at $37^{\circ} \mathrm{C}$ and $5 \% \mathrm{CO}_{2}$. The SFN was purchased from Sigma Chemical Co. (St. Louis, MO). A $20 \mathrm{mM}$ concentration stock solution was made by dissolving SFN in dimethyl sulfoxide (DMSO). The solution was stored in aliquots at $-20^{\circ} \mathrm{C}$. For the viability study, the cells were cultured in the presence or absence of various SFN concentrations for $48 \mathrm{~h}$. The cells were trypsinized and washed with phosphate-buffered saline (PBS), and the viable cells were scored using a hemocytometer with trypan blue exclusion.

Nuclear staining with DAPI. The cells were washed with cold PBS and fixed with $3.7 \%$ paraformaldehyde in PBS for $10 \mathrm{~min}$ at room temperature. The fixed cells were washed with PBS, and stained with a 4,6-diamidino-2-phenylindile (DAPI, Sigma Chemical Co.) solution for $10 \mathrm{~min}$ at room temperature. The cells were washed twice more with PBS and analyzed by fluorescent microscopy (Carl Zeiss, Germany).

Flow cytometry assay of apoptosis. The DNA content of the cells was measured using a DNA staining kit (CycleTest $^{\mathrm{TM}}$ Plus Kit, Becton-Dickinson, San Jose, CA). Propidium iodide (PI)-stained nuclear fractions were obtained using the instructions provided in the kit. The fluorescence intensity was determined using a FACScan flow cytometer and analyzed by CellQuest software (Becton-Dickinson). From the analysis of the DNA histograms, the percentage of cells in the different phases of the cell cycle was evaluated. Cells with a DNA content less than the G1 phase (sub-G1) were considered to be apoptotic.

$R N A$ extraction and $R T-P C R$. The total-RNA was prepared using an RNeasy kit (Qiagen, La Jolla, CA) and primed with random hexamers to synthesize the complementary DNA
Table I. Gene-specific primers for RT-PCR.

Name Sequence of primers

Bax

Sense 5'-ATG-GAC-GGG-TCC-GGG-GAG-3'

Antisense 5'-TGG-AAG-AAG-ATG-GGC-TGA-3'

Bcl-2

Sense 5'-CAG-CTG-CAC-CTG-ACG-3'

Antisense 5'-GCT-GGG-TAG-GTG-CAT-3'

$\mathrm{Bcl}-\mathrm{X}_{\mathrm{L}}$

Sense 5'-CAG-CTG-CAC-CTG-ACG-3'

Antisense 5'-GCT-GGG-TAG-GTG-CAT-3'

XIAP

Sense 5'-GAA-GAC-CCT-TGG-GAA-CAA-CA-3'

Antisense 5'-CGC-CTT-AGC-TGC-TCT-CTT-CAG-T-3'

cIAP-1

Sense 5'-TGA-GCA-TGC-AGA-CAC-ATG-C-3'

Antisense 5'-TGA-CGG-ATG-AAC-TCC-TGT-CC-3'

cIAP-2

Sense 5'-CAG-AAT-TGG-CAA-GAG-CTG-G-3'

Antisense 5'-CAC-TTG-CAA-GCT-GCT-CAG-G-3'

GAPDH

Sense 5'-CGG-AGT-CAA-CGG-ATT-TGG-TCG-TAT-3'

Antisense 5'-AGC-CTT-CTC-CAT-GGT-GGT-GAA-GAC-3'

using AMV reverse transcriptase (Amersham Corp., Arlington Heights, IL) according to the manufacturer's instructions. The polymerase chain reaction (PCR) was carried out in a Mastercycler (Eppendorf, Hamburg, Germany) with the primers shown in Table I. The conditions used for the PCR reactions were $1 \times\left(94^{\circ} \mathrm{C}\right.$ for $\left.3 \mathrm{~min}\right) ; 35 \times\left(94^{\circ} \mathrm{C}\right.$ for $45 \mathrm{sec}$; $58^{\circ} \mathrm{C}$ for $45 \mathrm{sec}$; and $72^{\circ} \mathrm{C}$ for $\left.1 \mathrm{~min}\right)$ and $1 \times\left(72^{\circ} \mathrm{C}\right.$ for $\left.10 \mathrm{~min}\right)$. The amplification products obtained by PCR were separated electrophoretically on $1 \%$ agarose gel and visualized by ethidium bromide (EtBr) staining.

Gel electrophoresis and Western blot analysis. The cells were harvested, lysed, and the protein concentrations were quantified using a Bio-Rad protein assay (Bio-Rad Lab., Hercules, CA) according to the manufacturer's instructions. Equal amounts of the protein were subjected to electrophoresis on SDSpolyacrylamide gels and transferred to nitrocellulose membranes (Schleicher \& Schuell, Keene, NH) by electroblotting. The blots were probed with the desired antibodies for $1 \mathrm{~h}$, incubated with the diluted enzyme-linked secondary antibodies and visualized by enhanced chemiluminescence (ECL) according to the recommended procedure (Amersham Corp.). The primary antibodies were purchased from Santa Cruz Biotechnology Inc. (Santa Cruz, CA) and Calbiochem (Cambridge, MA). The peroxidase-labeled donkey anti-rabbit immunoglobulin and peroxidase-labeled sheep anti-mouse immunoglobulin were purchased from Amersham. 
A)

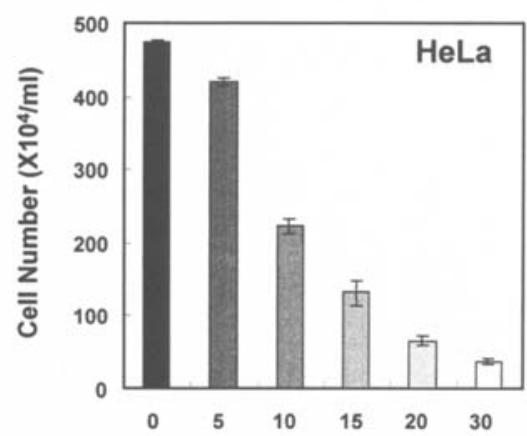

B)

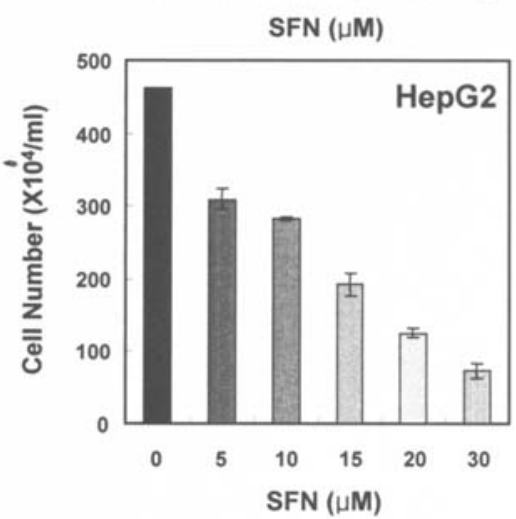

Figure 1. Inhibition of the cell viability by the SFN treatment in human cervical carcinoma HeLa and hepatcarcinoma HepG2 cells. The cells were treated with various concentrations of SFN for $48 \mathrm{~h}$ and the number of cells was estimated by trypan blue dye exclusion, as described in Materials and methods. The data shown are the means \pm SD of three independent experiments.

Assay of caspase-3 and caspase-9 activity. The enzymatic activity of the caspases induced by SFN was assayed using a colorimetric assay kit according to the manufacturer's instructions (R\&D Systems, Minneapolis, MN). Briefly, the cells were lysed in a lysis buffer for $30 \mathrm{~min}$ on an ice bath. The lysed cells were centrifuged at $14,000 \mathrm{rpm}$ for $10 \mathrm{~min}$, and $100 \mu \mathrm{g}$ of the protein was incubated with $50 \mu \mathrm{l}$ of a reaction buffer and $5 \mu 1$ of colorimetric tetrapeptides, Asp-Glu-ValAsp (DEVD)-p-nitroaniline (pNA) for caspase-3 and Leu-GluHis-Asp (LEHD)-pNA for caspase-9, respectively, at $37^{\circ} \mathrm{C}$ for $2 \mathrm{~h}$. The optical density of the reaction mixture was quantified spectrophotometrically at a wavelength of $405 \mathrm{~nm}$.

\section{Results}

Growth inhibition of HeLa and HepG2 cells by SFN treatment. The effects of SFN on the viability of HeLa and HepG2 cells were determined by treating the cells with different SFN concentrations and evaluating the cell viability using a trypan blue assay. As shown in Fig. 1, SFN inhibited the viability of both cell lines in a concentration-dependent manner. After $48 \mathrm{~h}$ of treatment, SFN at $20 \mu \mathrm{M}$ caused approximately $82 \%$ and $73 \%$ inhibition of cell growth in the HeLa and HepG2 cells compared with the controls, respectively.

Induction of apoptosis by SFN in HeLa and HepG2 cells. The HeLa and HepG2 cells treated with SFN were examined after DAPI staining in order to determine if the growth inhibition by SFN was associated with apoptotic cell death. The control
A)

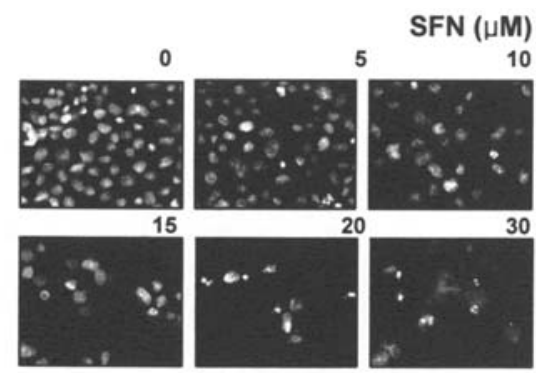

B)

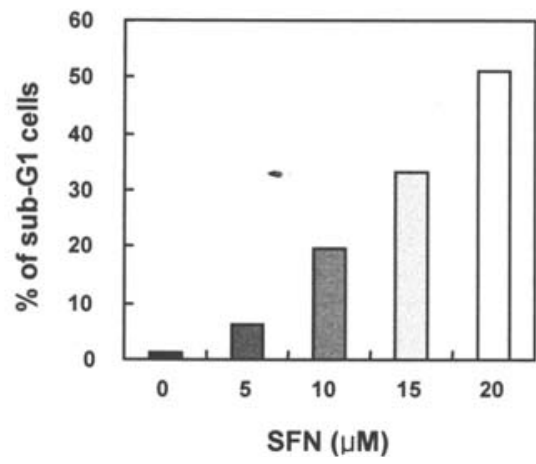

Figure 2. Induction of apoptosis by the SFN treatment in human cervical carcinoma HeLa cells. (A) The HeLa cells were incubated with various concentrations of SFN for $48 \mathrm{~h}$. The cells were sampled, fixed and stained with DAPI. After 10 min incubation at room temperature, the stained nuclei were observed under a fluorescent microscope using a blue filter. Magnification, $x 400$. (B) The cells were exposed to various SFN concentrations for $48 \mathrm{~h}$. The cells were collected and stained with PI for flow cytometry analysis. The percentage of cells with hypodiploid DNA contents represents the fractions undergoing apoptotic DNA degradation. The data represent the average of two independent experiments.

cells showed an intact nuclear structure, while the cells treated with SFN showed chromosomal condensation and the formation of apoptotic bodies in a concentration-dependent manner (Figs. 2A and 3A). The degree of apoptosis was quantified by analyzing the amount of sub-G1 DNA, which contained less DNA than the G1 cells, by flow cytometry of the fixed nuclei. As shown in Figs. 2B and 3B, the addition of SFN to the HeLa and HepG2 cells caused a marked increase in the accumulation of the sub-G1 phase. Overall, these results show that the growth inhibition observed in response to SFN is associated with the induction of apoptotic cell death.

Modulation of Bcl-2 family in SFN-treated HeLa and HepG2 cells. The apoptotic cascades involved by SFN in HeLa and HepG2 cells were examined by exposing the cells to SFN and comparing the levels of the Bcl-2 family members. RT-PCR and Western immunoblotting showed that the transcriptional and translational levels of Bax expression, a pro-apoptotic gene, were partly induced in the SFN treated HeLa cells, whereas the levels of anti-apoptotic Bcl-2 and $\mathrm{Bcl}-\mathrm{X}_{\mathrm{L}}$ in the HeLa cells were slightly inhibited in response to the SFN treatment (Fig. 4). In HepG2 cells, the levels of Bax mRNA and protein expression were not affected in the SFN-treated cells. However, the levels of Bcl-2 and $\mathrm{Bcl}-\mathrm{X}_{\mathrm{L}}$ expression were markedly down-regulated in response to the SFN treatment (Fig. 4).

Activation of caspase-3 by SFN treatment. The expression and activity of caspases such as capase- 3 and caspase- 9 in the 
A)

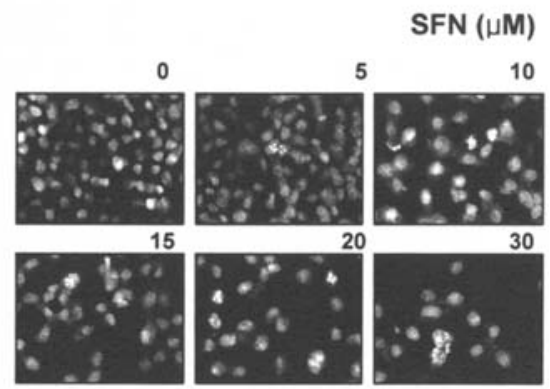

B)

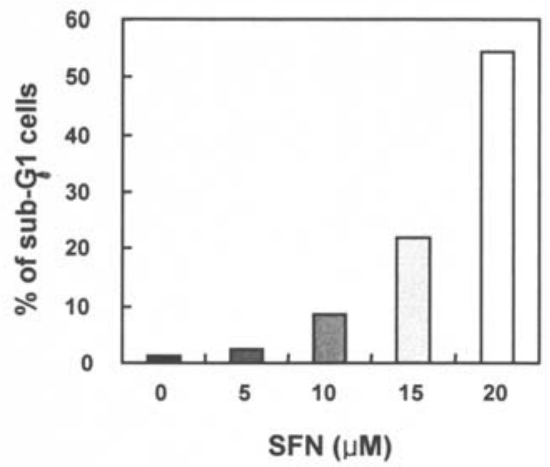

Figure 3. Induction of apoptosis by SFN treatment in human hepatocarcinoma HepG2 cells. (A) HepG2 cells were incubated with various concentrations of SFN for $48 \mathrm{~h}$. The cells were sampled, fixed and stained with DAPI. After $10 \mathrm{~min}$ incubation at room temperature, the stained nuclei were observed under a fluorescent microscope using a blue filter. Magnification, $\mathrm{x} 400$. (B) The cells were exposed for $48 \mathrm{~h}$ with various concentrations of SFN. The cells were collected and stained with PI for flow cytometry analysis. The percentage of cells containing hypodiploid DNA represents the fraction undergoing apoptotic DNA degradation. The data represent the averages of two independent experiments.
A)

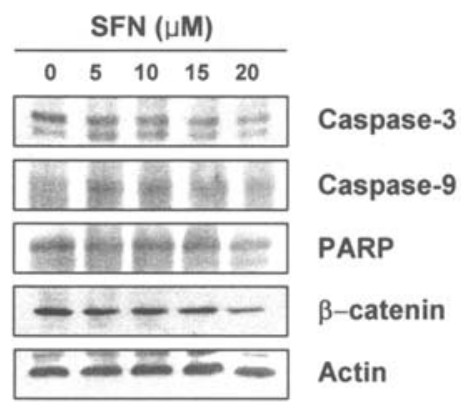

B)

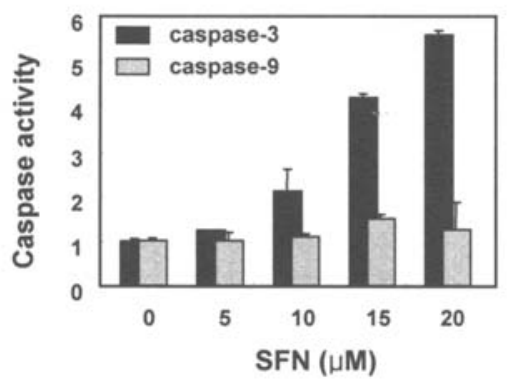

Figure 5. Activation of caspase- 3 by SFN treatment in human cervical carcinoma HeLa cells. (A) After $48 \mathrm{~h}$ incubation with SFN, the cells were lysed, and then cellular proteins were separated by SDS-polyacrylamide gels and transferred onto nitrocellulose membranes. The membranes were probed with anti-caspase-3, anti-caspase-9, anti-PARP and anti-ß-catenin antibodies. The proteins were visualized using an ECL detection system. Actin was used as the internal control. (B) After $48 \mathrm{~h}$ incubation with SFN, the aliquots were incubated with the substrates, DEVD-pNA and LEHD-pNA, to determine the in vitro caspase- 3 and caspase- 9 activity, respectively, at $37^{\circ} \mathrm{C}$ for $1 \mathrm{~h}$. The released fluorescent products were measured. The data are reported as the mean values from three independent experiments and the bars represent the standard deviations.

SFN-treated HeLa and HepG2 cells was next examined by Western blot analysis and an in vitro activity assay. The results showed that the SFN treatment down-regulated the levels of the pro-caspase-3 protein but the pro-caspase-9 levels remained unchanged in both cell lines (Figs. 5A and 6A). In order to further quantify the proteolytic activation of caspase-3 and -9 , the lysates equalized for protein from the cells treated with SFN were assayed for their caspase-3 and -9 activity using DEVD-pNA and LEHD-pNA as substrates, respectively. As shown in Figs. 5B and 6B, SFN increased the activity of caspase-3 in both HeLA and HepG2 cells in a concentration-dependent manner but had no effect on caspase-9. Furthermore, SFN induced the concomitant degradation and/or down-regulation of poly(ADP-ribose) polymerase (PARP) and $B$-catenin, which are substrate proteins of caspase-3 (Figs. 5A and 6A).

Effects of SFN on the levels of IAP family. On the other hand, the IAP family proteins bind to caspases, which lead to caspase inactivation in eukaryotic cells. Therefore, the involvement of the IAP family in the SFN-induced apoptosis of HeLa and HepG2 cells was further examined. The results showed that the levels of the IAPs family members such as XIAP, cIAP-1 and cIAP-2, remained unchanged or slightly down-regulated in the SFN-treated HeLa cells (Fig. 7).

Figure 4. Effects of SFN on the levels of the Bck-2 family members in human incubation with SFN, the total-RNA was isolated and reverse-transcribed. The resulting cDNA was subjected to PCR with Bax, Bcl-2 and $\mathrm{Bcl}-\mathrm{X}_{\mathrm{L}}$ primers. The reaction products were subjected to electrophoresis in $1 \%$ agarose gel and visualized by EtBr staining. GAPDH was used as the internal control. (B) The cells were lysed and the cellular proteins were then separated by SDS-polyacrylamide gels and transferred onto nitrocellulose membranes. The membranes were probed with the anti-Bax, anti-Bcl-2 and anti-Bcl- $\mathrm{X}_{\mathrm{L}}$ antibodies. The proteins were visualized using an ECL detection system. Actin was used as the internal control. 
A)

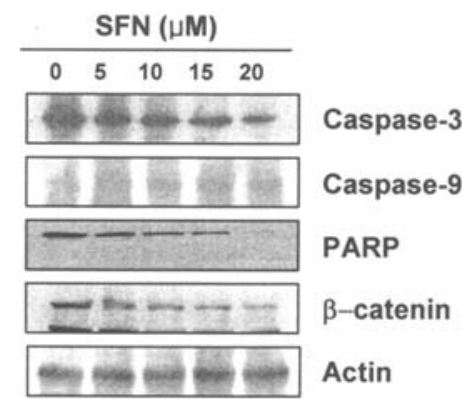

B)

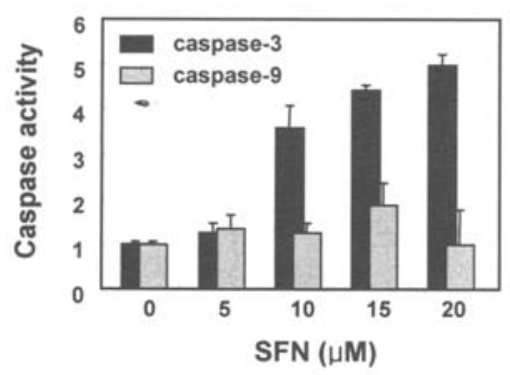

Figure 6. Activation of caspase- 3 by SFN treatment in human hepatocarcinoma HepG2 cells. (A) After $48 \mathrm{~h}$ incubation with SFN, the cells were lysed. The cellular proteins were then separated by SDS-polyacrylamide gels and transferred onto a nitrocellulose membrane. The membranes were probed with anti-caspase-3, anti-caspase- 9 , anti-PARP and anti- $\beta$-catenin antibodies. The proteins were visualized using an ECL detection system. Actin was used as the internal control. (B) After $48 \mathrm{~h}$ incubation with SFN, the aliquots were incubated with substrates, DEVD-pNA and LEHD-pNA, to determine the in vitro caspase- 3 and caspase- 9 activity, respectively, at $37^{\circ} \mathrm{C}$ for $1 \mathrm{~h}$. The released fluorescent products were measured. The data are reported as the mean values from three independent experiments and the bars represent the standard deviations.

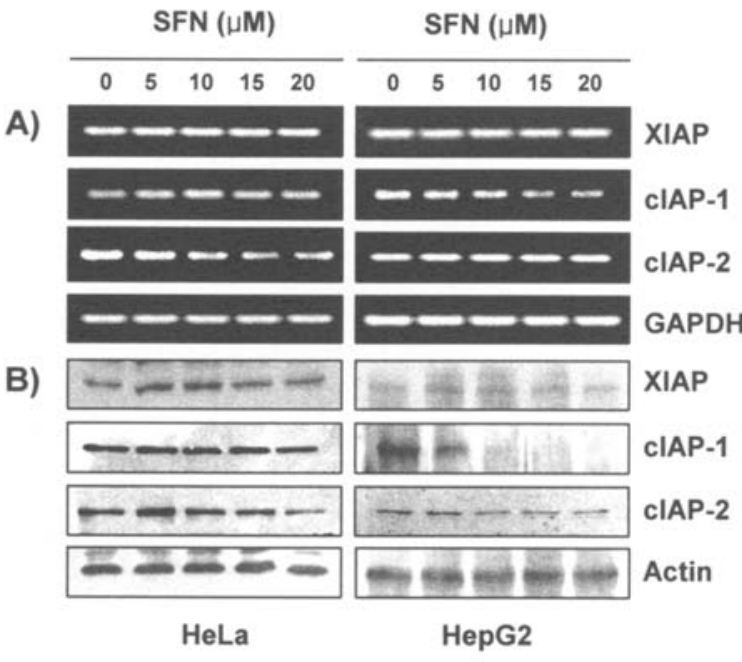

Figure 7. Effects of SFN on the levels of the IAP family members in human cervical carcinoma HeLa and hepatocarcinoma HepG2 cells. (A) After $48 \mathrm{~h}$ incubation with SFN, the total-RNA was isolated and reverse-transcribed. The resulting cDNA was subjected to PCR with the indicated primers and the reaction products were subjected to electrophoresis in $1 \%$ agarose gel and visualized by EtBr staining. GAPDH was used as the internal control. (B) The cells were lysed and the cellular proteins were separated by SDSpolyacrylamide gels and transferred onto nitrocellulose membranes. The membranes were probed with the indicated antibodies. The proteins were visualized using an ECL detection system. Actin was used as the internal control.
A)

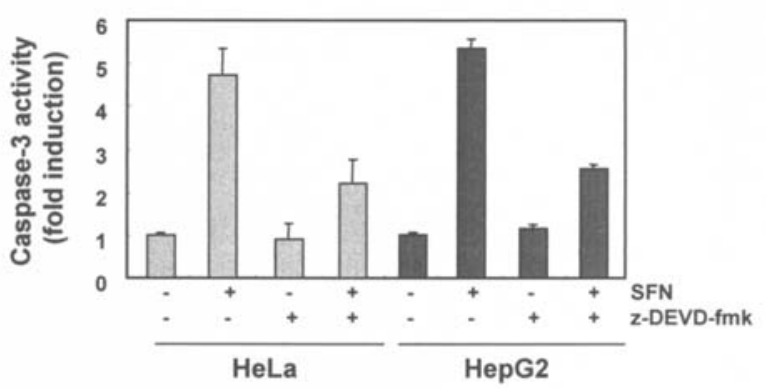

B)

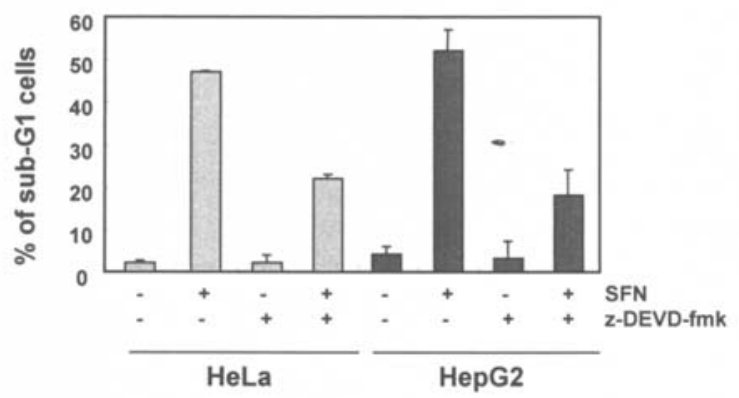

Figure 8. Inhibition of SFN-induced caspase-3 activation and apoptosis by z-DEVD-fmk, a caspase-3 inhibitor, in human cervical carcinoma HeLa and hepatocarcinoma HepG2 cells. (A) The cells were treated with z-DEVDfmk $(50 \mu \mathrm{M})$ for $1 \mathrm{~h}$ before challenge with $20 \mu \mathrm{M} \mathrm{SFN}$ for $48 \mathrm{~h}$. The cell lysates were made, and used to measure the caspase- 3 activity using DEVDpNA, a caspase-3 substrate. (B) The cells grown under the same conditions as (A) were evaluated for their sub-G1 DNA content by flow cytometry. The data are reported as the mean $\pm \mathrm{SE}$ of three independent experiments.

However, the levels of cIAP-1 expression were markedly inhibited in the SFN-treated HepG2 cells without altering the XIAP and cIAP-2 expression levels.

Inhibition of SFN-induced apoptosis by caspase-3 inhibitor. In order to demonstrate that the activation of caspase- 3 is a key step in the apoptotic pathway induced by SFN, HeLa and HepG3 cells were pretreated with z-DEVD-fmk $(50 \mu \mathrm{M})$, a cell-permeable caspase- 3 inhibitor, for $1 \mathrm{~h}$, followed by a treatment with $20 \mu \mathrm{M} \mathrm{SFN}$ for $48 \mathrm{~h}$. As shown in Fig. 8, pretreatment of the cells with z-DEVD-fmk significantly blocked not only caspase- 3 activation but also the increase in the sub-G1 population. These results clearly show that SFN-induced apoptosis is associated with the activation of caspase-3.

\section{Discussion}

Recently, there has been increasing interest in the use of isothiocyanate SFN as a cancer chemopreventive and a therapeutic agent. Many studies have reported that an SFN treatment caused the accumulation of cells in the G2/M phase of the cell cycle, suggesting that the growth inhibitory effect of SFN is the result of a block during the $\mathrm{G} 2 / \mathrm{M}$ phase and that such cells do not enter the G1 phase $(12,14,16,18-20)$. While the cell killing mechanism of SFN has been suggested (13,15-17,21-24), little is known about the effects of this compound on the growth of human cervical carcinoma and hepatocarcinoma cells. Therefore, this study investigated the 
effects of SFN on the growth of human cervical carcinoma cells, HeLa and hepatocarcinoma HepG2 cells in order to examine the mechanisms of its anti-proliferative pathway. These results clearly show that SFN inhibits the cell viability and induces apoptosis in both HeLa and HepG2 cells, which appears to account for its anti-proliferating activity. The induction of apoptosis by SFN was confirmed by the characteristic morphological changes and the increase in the sub-G1 cells of the cell cycle (Figs. 2 and 3).

Apoptosis is tightly regulated by a number of gene products that promote or block cell death at different stages. The Bcl-2 family is the most extensively studied and perhaps the most important $(25,26)$. The caspase family also plays an important role in driving apoptosis. They are synthesized initially as single polypeptide chains representing the latent precursors that undergo proteolytic processing at specific residues to produce the subunits that form an active heterotetrameric protease $(4,27)$. In mammals, members of the Bcl-2 family can be divided into two subfamilies; the anti-apoptotic protein family such as Bcl-2 and $\mathrm{Bcl}-\mathrm{X}_{\mathrm{L}}$, and the pro-apoptotic protein family such as Bax and Bak. These molecules either homodimerize or heterodimerize with the molecules with an opposing function (28). Therefore, it was suggested that the ratio between the level of pro-apoptotic Bax protein and that of the anti-apoptotic factor, Bcl-2, determines if a cell responds to an apoptotic signal. It has recently become evident that the mitochondria play a key role in apoptosis (26). Bax and adenine nucleotide translocator cooperate within the permeability transition pore complex to increase the mitochondrial membrane permeability, and discharge a number of apoptogenic molecules into the cytosol (29). A well-known apoptogenic factor released from the permeabilized mitochondria is the respiratory component cytochrome $c$, which recruits the apoptosis protease activating factor (Apaf-1) and pro-caspase-9 to form apoptosomes. Caspase-9 is then activated, and orchestrates caspase- 3 and other effector molecules for cell death (30).

In addition, the IAP family members have been reported to have anti-apoptotic effects as a result of their function as direct inhibitors of activated caspases (3, 7 and 9), regulating cell cycle progression and modulating receptor-mediated signal transduction $(5,31)$. Therefore, the down-regulation of IAPs relieves the triggering block of proapoptotic signaling and the execution caspases, thus activating cell death $(3,32)$. Activated caspases induce limited proteolysis in many cellular proteins, which are degraded by the caspase family as a consequence of apoptosis, and have been used as markers of chemotherapy-induced apoptosis $(33,34)$. In this study, SFNinduced apoptosis was accompanied by the down-regulation of $\mathrm{Bcl}-2 / \mathrm{Bcl}-\mathrm{X}_{\mathrm{L}}$ and the selective down-regulation of IAP family members in HeLa and HepG2 cells (Figs. 4 and 7). Moreover, the SFN treatment caused the activation of caspase-3 but not caspase- 9 in a concentration-response manner. This is consistent with the degradation of PARP and the $\beta$-catenin proteins, which are downstream targets of activated caspase-3 (Figs. 5 and 6). Under the same conditions, z-DEVD-fmk, a caspase-3 inhibitor, markedly prevented SFNinduced apoptosis by blocking caspase-3 activation (Fig. 8). This suggests that caspase- 3 play a key molecule in the apoptosis of U937 by SFN.
In summary, SFN induces apoptosis in HeLa cervical carcinoma and HepG2 hepatocarcinoma cells, which appears to account for its anti-proliferative activity. These apoptotic mechanisms were mediated by a modulation of the Bcl-2 family, the activation of caspase- 3 and the selective downregulation of the IAP family. These results provide further information on the possible mechanisms for the anticancer activity of SFN.

\section{Acknowledgements}

This study was supported by Korea Research Foundation Grant (KRF-2004-005-E00007).

\section{References}

1. Walker PR and Sikorska M: New aspects of the mechanism of DNA fragmentation in apoptosis. Biochem Cell Biol 75: 287-299, 1997.

2. Robertson JD and Orrenius S: Molecular mechanisms of apoptosis induced by cytotoxic chemicals. Crit Rev Toxicol 30: 609-627, 2000.

3. Hengartner MO: The biochemistry of apoptosis. Nature 407: 770-776, 2000.

4. Stennicke HR and Salvesen GS: Caspases - controlling intracellular signals by protease zymogen activation. Biochim Biophys Acta 1477: 299-306, 2000.

5. Deveraux QL and Reed JC: IAP family proteins - suppressors of apoptosis. Genes Dev 13: 239-252, 1999.

6. Riboli E and Norat T: Epidemiologic evidence of the protective effect of fruits and vegetables on cancer risk. Am J Clin Nutr 78: S559-S569, 2003.

7. Fahey JW, Zalcmann AT and Talalay P: The chemical diversity and distribution of glucosinolates and isothiocyanates among plants. Phytochemistry 56: 5-51, 2001

8. Zhang Y and Talalay P: Anticarcinogenic activities of organic isothiocyanates: chemistry and mechanisms. Cancer Res 54: S1976-S1981, 1994.

9. Hecht SS: Chemoprevention of cancer by isothiocyanates, modifiers of carcinogen metabolism. J Nutr 129: S768-S774, 1999.

10. Maheo K, Morel F, Langouet S, Kramer H, Le Ferrec E, Ketterer B and Guillouzo A: Inhibition of cytochromes P-450 and induction of glutathione S-transferases by sulforaphane in primary human and rat hepatocytes. Cancer Res 57: 3649-3652, 1997.

11. Yang CS, Smith TJ and Hong JY: Cytochrome P-450 enzymes as targets for chemoprevention against chemical carcinogenesis and toxicity: opportunities and limitations. Cancer Res 54: S1982-S1986, 1994.

12. Keck AS, Staack R and Jeffery EH: The cruciferous nitrile crambene has bioactivity similar to sulforaphane when administered to Fischer 344 rats but is far less potent in cell culture. Nutr Cancer 42: 233-240, 2002.

13. Jackson SJ and Singletary KW: Sulforaphane: a naturally occurring mammary carcinoma mitotic inhibitor, which disrupts tubulin polymerization. Carcinogenesis 25: 219-227, 2004

14. Parnaud G, Li P, Cassar G, Rouimi P, Tulliez J, Combaret L and Gamet-Payrastre L: Mechanism of sulforaphane-induced cell cycle arrest and apoptosis in human colon cancer cells. Nutr Cancer 48: 198-206, 2004.

15. Wang L, Liu D, Ahmed T, Chung FL, Conaway C and Chiao JW: Targeting cell cycle machinery as a molecular mechanism of sulforaphane in prostate cancer prevention. Int J Oncol 24: 187-192, 2004.

16. Singh SV, Herman-Antosiewicz A, Singh AV, Lew KL, Srivastava SK, Kamath R, Brown KD, Zhang L and Baskaran R: Sulforaphane-induced G2/M phase cell cycle arrest involves checkpoint kinase 2-mediated phosphorylation of cell division cycle 25C. J Biol Chem 279: 25813-25822, 2004.

17. Singh SV, Srivastava SK, Choi S, Lew KL, Antosiewicz J, Xiao D, Zeng Y, Watkins SC, Johnson CS, Trump DL, Lee YJ, Xiao H and Herman-Antosiewicz A: Sulforaphane-induced cell death in human prostate cancer cells is initiated by reactive oxygen species. J Biol Chem 280: 19911-19924, 2005. 
18. Cho SD, Li G, Hu H, Jiang C, Kang KS, Lee YS, Kim SH and $\mathrm{Lu} \mathrm{J}$ : Involvement of c-Jun N-terminal kinase in G2/M arrest and caspase-mediated apoptosis induced by sulforaphane in DU145 prostate cancer cells. Nutr Cancer 52: 213-224, 2005.

19. Jakubikova J, Bao Y and Sedlak J: Isothiocyanates induce cell cycle arrest, apoptosis and mitochondrial potential depolarization in HL-60 and multidrug-resistant cell lines. Anticancer Res 25: 3375-3386, 2005.

20. Jakubikova J, Sedlak J, Mithen R and Bao Y: Role of PI3K/Akt and MEK/ERK signaling pathways in sulforaphane- and erucininduced phase II enzymes and MRP2 transcription, G2/M arrest and cell death in Caco-2 cells. Biochem Pharmacol 69: 1543-1552, 2005.

21. Tang L and Zhang Y: Mitochondria are the primary target in isothiocyanate-induced apoptosis in human bladder cancer cells. Mol Cancer Ther 4: 1250-1259, 2005.

22. Choi S and Singh SV: Bax and Bak are required for apoptosis induction by sulforaphane, a cruciferous vegetable-derived cancer chemopreventive agent. Cancer Res 65: 2035-2043, 2005.

23. Karmakar S, Weinberg MS, Banik NL, Patel SJ and Ray SK: Activation of multiple molecular mechanisms for apoptosis in human malignant glioblastoma T98G and U87MG cells treated with sulforaphane. Neuroscience 141: 1265-1280, 2006.

25. Reed JC: Bcl-2 family proteins: regulators of apoptosis and chemoresistance in hematologic malignancies. Semin Hematol 34: S9-S19, 1997.

24. Pappa G, Lichtenberg M, Iori R, Barillari J, Bartsch H and Gerhauser C: Comparison of growth inhibition profiles and mechanisms of apoptosis induction in human colon cancer cell lines by isothiocyanates and indoles from Brassicaceae. Mutat Res 599: 76-87, 2006.
26. Pellecchia $\mathrm{M}$ and Reed JC: Inhibition of anti-apoptotic Bcl-2 family proteins by natural polyphenols: new avenues for cancer chemoprevention and chemotherapy. Curr Pharm Des 10: 1387-1398, 2004.

28. Oltvai ZN, Milliman CL and Korsmeyer SJ: Bcl-2 heterodimerizes in vivo with a conserved homolog, Bax, that accelerates programmed cell death. Cell 74: 609-619, 1993.

27. Philchenkov A, Zavelevich M, Kroczak TJ and Los M: Caspases and cancer: mechanisms of inactivation and new treatment modalities. Exp Oncol 26: 82-97, 2004.

29. Marzo I, Brenner C and Kroemer G: The central role of the mitochondrial megachannel in apoptosis: evidence obtained with intact cells, isolated mitochondria and purified protein complexes. Biomed Pharmacother 52: 248-251, 1998.

30. Rodriguez $\mathbf{J}$ and Lazebnik Y: Caspase-9 and APAF-1 form an active holoenzyme. Genes Dev 13: 3179-3184, 1999.

31. Roy N, Deveraux QL, Takahashi R, Salvesen GS and Reed JC: The c-IAP-1 and c-IAP-2 proteins are direct inhibitors of specific caspases. EMBO J 16: 6914-6925, 1997.

32. Daniel PT, Schulze-Osthoff K, Belka C and Guner D: Guardians of cell death: the Bcl-2 family proteins. Essays Biochem 39: 73-88, 2003.

33. Bae SS, Perry DK, Oh YS, Choi JH, Galadari SH, Ghayur T, Ryu SH, Hannun YA and Suh PG: Proteolytic cleavage of phospholipase $\mathrm{C}-\gamma 1$ during apoptosis in Molt- 4 cells. FASEB J 14: 1083-1092, 2000

34. Kaufmann SH, Desnoyers S, Ottaviano Y, Davidson NE and Poirier GG: Specific proteolytic cleavage of poly(ADP-ribose) polymerase: an early marker of chemotherapy-induced apoptosis. Cancer Res 53: 3976-3985, 1993. 